Conclusion: COVID-19 does not look extremely dangerous in patients with rheumatic diseases, used target DMARDs. Used of tsDMARDs doesn't reliably increase the risk of COVID-19 severity. There is reliable correlation between age and COVID-19 severity.

Table 1. Cohort characteristics

\begin{tabular}{llllll}
\hline Drugs & Mean age & $\begin{array}{l}\text { Number of } \\
\text { patients }\end{array}$ & $\begin{array}{l}\text { Patients } \\
\text { with } \\
\text { symptoms }\end{array}$ & Hospitalized patients & $\begin{array}{l}\text { Asymptomatic } \\
\text { course }\end{array}$ \\
\hline Adalimumab & $41,0 \pm 11,4$ & 10 & 9 & 2 & 1 \\
Golimumab & $51,0 \pm 11,03$ & 4 & 4 & 0 & 0 \\
Infliximab & $42,7 \pm 11,8$ & 4 & 0 & 0 & 4 \\
Certolizumab & $41,6 \pm 11,7$ & 3 & 3 & 0 & 0 \\
Etanercept & $50,7 \pm 11,4$ & 22 & 20 & 6 & 2 \\
Tofacitinib & $56,8 \pm 10,4$ & 13 & 12 & 2 & 1 \\
Abatacept & $57,4 \pm 10,9$ & 5 & 4 & 1 & 2 \\
Tocilizumab & $48,8 \pm 10.9$ & 5 & 3 & 1 & 0 \\
Rituximab & $55,6 \pm 10,7$ & 3 & 3 & 1 & 0 \\
Netakimab & $44,0 \pm 15,8$ & 2 & 2 & 1 & 1 \\
Ustekinumab & $48,0 \pm 10,5$ & 2 & 1 & 0 & 1 \\
\hline
\end{tabular}

Disclosure of Interests: None declared

DOI: 10.1136/annrheumdis-2021-eular.3867

\begin{tabular}{l|l}
\hline AB0704 & TELEMEDICINE AT THE TIME OF COVID-19: THE \\
& EXPERIENCE WITH RA PATIENTS TREATED WITH \\
& JAK-INHIBITORS
\end{tabular}

C. Garufi ${ }^{1}$, F. R. Spinelli ${ }^{1}$, S. Mancuso ${ }^{1}$, F. Ceccarelli ${ }^{1}$, F. Conti ${ }^{1}{ }^{1}$ Sapienza University of Rome, Reumatologia, Dipartimento di Dipartimento di Scienze Cliniche Internistiche, Anestesiologiche e Cardiovascolari, Roma, Italy

Background: The spread of COVID-19, the lockdown, the limited access to care reevaluated the role of tele-consultation and self-assessment.

Objectives: Our aim was to evaluate in a cohort of Rheumatoid Arthritis (RA) patients treated with JAK-inhibitors (JAKi): the self-assessed disease activity during lockdown, the lockdown impact on fatigue, anxiety, depression and the prevalence of Covid-19.

Methods: We enrolled RA patients treated with baricitinib or tofacitinib. At baseline $(\mathrm{BL})$ and follow-up we collected: patients' demographic data, composite disease activity indices (CDAI, DAS28 ${ }_{\text {CRP }}$ ), global assessment (PGA), pain visual analogue scale (VAS), FACIT (functional assessment of chronic illness therapy) and a self-rating scale for disease impact on anxiety and depression (Zung-A/D). Patients were instructed on how to perform self-assessment through video-material and fulfilled the online form of "Rheumatoid Arthritis Impact of Disease" $(\mathrm{RAID})^{1}$ and "RA Disease Activity Index" (RADAI). To capture the pandemic effect, we compared patients in different status (remission, low, moderate and high-disease activity) at the last in-person visit (preCoV) through the DAS28 and CDAI, to the tele-health visit (THV), measured by the RAID. BL and pre-CoV ZUNG-A, ZUNG-D, FACIT questionnaires were compared with the online results during the pandemic. Exposure, tests and symptoms of Covid-19 were recorded. Data were expressed as mean \pm standard deviation or median (IQR) according to distribution.

Results: Twenty patients (median age $58.2 \pm 11.9$ and mean disease duration $153.5 \pm 112.7$ months) were treated with tofacitinib and 27 with baricitinib. The median time-lapse between the pre-CoV visit and the THV was 12 (IQR 4) weeks. DAS28CRP and CDAl significantly decreased from BL to pre-CoV visit. During the last in-person visit, 21 patients $(48.83 \%)$ were in remission, $9(20.93 \%)$ in low disease activity; according to the RAID, 15 (31.91\%) and 7 (14.89\%) patients were respectively in remission and low disease activity during the THV (Table A). PGA and pain significantly decreased from $B L$ to pre-Cov visit but worsened during the lockdown (Table A). FACIT remaining stable during THV. At THV, we detected a significant improvement of anxiety from $B L$ (Zung-A) and a tendency to lower depression scores compared to BL (Table A). JAKi showed a good safety profile considering Covid-19 symptoms, none of the patients was diagnosed with SarsCoV2 infection.

Conclusion: This is the first study on virtual assessment in RA patients treated with JAKi. The unique social experiment of the pandemic impaired the clinical response already achieved before the lockdown, without a collateral worseling of FACIT, anxiety and depression.

REFERENCES:

[1] Gossec L, et al. Ann Rheum Dis. 2009

[2] Stucki G, et al. Arthritis Rheum. 1995
Table A. DAS28, CDAI, RAID scores and patient-reported outcomes assessment at baseline and during the follow-up

\begin{tabular}{lcccc}
\hline & & BL & pre-CoV & THV \\
\hline DISEASE ACTIVITY & & $\mathbf{N}(\%)$ & $\mathbf{N}(\%)$ & $\mathbf{N}(\%)$ \\
\hline REMISSION & DAS28 & $0(0 \%)$ & $21(48.8 \%)$ & \\
& CDAI & $0(0 \%)$ & $10(22.7 \%)$ & $15(31.9 \%)$ \\
LOW DISEASE & RAID & & & \\
& DAS28 & $1(2.1 \%)$ & $9(20.9 \%)$ & \\
MODERATE & CDAI & $7(14.8 \%)$ & $23(52.2 \%)$ & $7(14.9 \%)$ \\
& RAID & & & \\
HIGH & DAS28 & $33(70.2 \%)$ & $12(27.9 \%)$ & $13(27.6 \%)$ \\
& CDAI & $17(37.1 \%)$ & $8(18.1 \%)$ & \\
GH & RAID & $13(27.6 \%)$ & $1(2.3 \%)$ & $12(25.5 \%)$ \\
Pain & DAS28 & $23(48.9 \%)$ & $3(6.8 \%)$ & $45(45)^{\star} \#$ \\
Zung A & CDAI & & & \\
Zung-D & RAID & $70(30)$ & $20(49.5)^{*}$ & $(48.5)^{\star} \#$ \\
FACIT & & $70(28)$ & $25(45.5)^{*}$ & $35(14)^{*}$ \\
& & $37(9)$ & $37(10.2)$ & $38(12)$ \\
\hline
\end{tabular}

${ }^{*} p \leq 0.001$ vs BL\# $p \leq 0.04$ vs preCoVData expressed as median (IQR)

Disclosure of Interests: Cristina Garufi: None declared, Francesca Romana Spinelli Speakers bureau: Abbvie, Eli Lilly, Consultant of: Gilead/Galapagos, Eli Lilly, Grant/research support from: Pfizer, Silvia Mancuso: None declared, Fulvia Ceccarelli: None declared, Fabrizio Conti Speakers bureau: Abbvie, Eli Lilly, Sanofi, Pfizer, Consultant of: Gilead/Galapagos

DOI: 10.1136/annrheumdis-2021-eular.3892

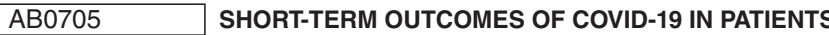 WITH RHEUMATIC DISEASES WHO ARE TREATED BY BIOLOGICAL AND TARGETED SYNTHETIC DMARDS: OBSERVATIONAL SINGLE-CENTER STUDY}

E. Luchikhina ${ }^{1}$, D. Karateev ${ }^{1}$, O. Semenova ${ }^{1}$, O. Matveychuk ${ }^{1}$, T. Kuznetsova ${ }^{1}$

${ }^{1}$ Moscow Regional Research and Clinical Institute n.a. M.F. Vladimirsky (MONIKI), Moscow Regional Rheumatology Center and Department of Rheumatology, Moscow, Russian Federation

Background: The course of new coronavirus infection in patients with rheumatic diseases $(\mathrm{RD})$ undergoing treatment with biological and targeted drugs is still poorly understood.

Objectives: To study outcomes of COVID-19 in patients with RD receiving treatment biological and targeted synthetic DMARDs.

Methods: We studied cases of COVID-19 in patients with RD, included in "Moscow regional registry of patients with rheumatic diseases receiving treatmen with biological and targeted synthetic drugs" - observational cohort, started in 2018. A total number of patients, included in the registry, is 1048 at December 2020.

Results: By January 2021, 44 known cases of COVID-19 were registered among patients included in the registry (4,2\%). This group included $29(65,9 \%)$ females, $15(34,1 \%$ ) males, with mean age 45,09 $\pm 12,7$ (median 47,0 [34,0; 57,0]) y.o. The vast majority of patients had rheumatoid arthritis $(19,43,2 \%)$ and ankylosing spondylitis $(19,43,2 \%)$, there were $3(6,8 \%)$ patients with psoriatic arthritis, and one patient each $(2,3 \%)$ with systemic lupus erythematosus, systemic sclerosis, and ANCA-vasculitis. Before COVID-19, 20 (45,5\%) patients received TNF inhibitors (adalimumab, infliximab, etanercept, certolizumab, golimumab) $7(15,9 \%)$ - IL-6 receptor inhibitors (tocilizumab, sarilumab), $7(15,9 \%)$ - ritux imab (period between last infusion and COVID-19 was 1-4 months), $5(11,4 \%)$ - sekukinumab, $2(4,5 \%)$ - tofacitinib, and one patient each $(2,3 \%)$ received abatacept and ustekinumab. Also, $22(50 \%)$ received methotrexate, $4(9,1 \%)$ - leflunomide, $3(6,8 \%)$ - mycophenolate mofetil, 1 (2,3\%) - sulfasalazine; 12 $(27,3 \%)$ took oral steroids. COVID-19 presented as mild disease in $23(52,3 \%)$ patients, and $21(47,7 \%)$ had viral interstitial pneumonia verified by computed tomography. $16(36,4 \%)$ patients were hospitalized, only one patient underwent artificial lung ventilation. We found no significant associations between particular diagnosis and treatment on the one hand, and hospitalization for COVID19 on the other hand. For treatment of COVID-19, two (4,5\%) patients did no receive any medications, and the rest of patients received antiviral and antibacterial therapy according to standardized protocol. In addition, corticosteroids were administered for COVID-19 in $15(34,1 \%)$ patients, mainly (12 cases) in hospital, and two $(4,5 \%)$ patients in hospital were treated by tocilizumab. The outcome in all cases was favorable, all patients successfully recovered from the new coronavirus infection. 
Conclusion: In this observational study, we found no association between biologic and targeted therapy for rheumatic diseases and severe course of new coronavirus infection, as well as with the need for hospitalization for COVID-19. The outcome of COVID-19 was favorable in all patients receiving treatment with biological and targeted synthetic drugs for rheumatic diseases.

Disclosure of Interests: None declared

DOI: 10.1136/annrheumdis-2021-eular.3997

\section{AB0706 1 ASSOCIATED RISK FACTORS AND OUTCOMES IN HOSPITALISED COVID-19 PATIENTS WITH BIOLOGICS AND JAK-INHIBITORS: A REPORT FROM A CENTER SPECIALISED IN IMMUNE-MEDIATED DISEASES}

A. M. Anzola Alfaro ${ }^{1,2,3}$, L. R. Caballero Motta ${ }^{1,2,3}$, J. C. Nieto González ${ }^{1,2,3}$, L. Menchen Viso ${ }^{4,5}$, O. Baniandrés ${ }^{4,6}$, C. Lobo Rodríguez ${ }^{5}$, I. Monteagudo ${ }^{1,2,3}$ J. M. Alvaro Gracia ${ }^{1,2,3}$, C. Gonzalez ${ }^{3,7,8}$ ' $^{1}$ Gregorio Marañón Hospital, Rheumatology, Madrid, Spain; ${ }^{2}$ Centro de Enfermedades Inflamatorias Mediadas por la Inmunidad (CEIMI), Rheumatology, Madrid, Spain; ${ }^{3}$ Fundación Investigación Biomedica Hospital Gregorio Marañón, Rheumatology, Madrid, Spain; ${ }^{4}$ Gregorio Marañón Hospital, Gastroenterology, Madrid, Spain; ${ }^{5}$ Centro de Enfermedades Inflamatorias Mediadas por la Inmunidad (CEIMI), Nurse Supervisor, Madrid, Spain; ${ }^{6}$ Centro de Enfermedades Inflamatorias Mediadas por la Inmunidad (CEIMI), Gastroenterology, Madrid, Spain; ${ }^{7}$ Centro de Enfermedades Inflamatorias Mediadas por la Inmunidad (CEIMI), Dermatology, Madrid, Spain; ${ }^{8}$ Gregorio Marañón Hospital, Dermatology, Madrid, Spain

Background: There's little data of patients with immune diseases (ID) treated with biologic and JAK-inhibitors and COVID19. Current consensus is to keep treatment, however more studies are needed to ascertain the risk in these patients.

Objectives: To describe the associated risk factors and outcomes in hospitalized patients with ID treated with biologics and JAK-inhibitors of a tertiary center. Methods: Observational retrospective study of patients with COVID19 from March $1^{\text {st }} 2020$ to January $31^{\text {st }} 2021$. Out of all the patients receiving subcutaneous (SC) or intravenous (IV) biologics and oral (PO) JAK-inhibitors, we selected those requiring hospitalization due to pneumonia for analysis. We collected demographic data, comorbidities, seasonal flu vaccination, smoking history and the outcome (discharge/admission in an intensive care unit (ICU)/death). We used a composite index (Charlston's index) for comorbidities.

Results: Of 153 patients, 29 (18.9\%) were hospitalized. 18 (62\%) were women with a median age of 61 (IQ 52-69). 14 (48.2\%) had rheumatoid arthritis, 5 (17\%) had axial spondylarthritis and $4(13.7 \%)$ had Chron's disease. The main IV was Rituximab in $3(50 \%)$, and abatacept, infliximab and vedolizumab had one each. Of the SC, tocilizumab and adalimumab had $5(22.7 \%)$ each, etanecept and golimumab had $3(13.6 \%)$ each and secukinumab, ustekinumab and abatacept had $2(9 \%)$ each. The PO was tofacitinib. There were no outcome differences for each treatment.

$24(82.7 \%)$ patients had at least 1 comorbidity with significative difference between patients (Table 1$)$. There were $6(20.6 \%)$ deaths, $3(50 \%)$ in the ICU, 2 (33\%) did not meet the ICU criteria, and 1 (16\%) before ICU admission. None them had the same ID.

Table 1. Baseline data.

\begin{tabular}{|c|c|c|c|c|}
\hline Variables, (\%) & $\begin{array}{c}\text { Total } \\
29(100)\end{array}$ & Deaths 6 (20.6) & $\begin{array}{c}\text { Discharged } \\
23(79.3)\end{array}$ & $\mathbf{P}$ \\
\hline Women (\%) & $18(62)$ & $4(66.6)$ & $14(61)$ & 0.79 \\
\hline Age, Median (IQ range) & $61(52-69)$ & $69.5(62-78.5)$ & $59.9(51-65.5)$ & 0.09 \\
\hline Flu vaccine $(\%)$ & $15(51.7)$ & $5(83.3)$ & $10(43.7)$ & 0.08 \\
\hline ICU $(\%)$ & $8(27.5)$ & $3(50)$ & $5(22)$ & 0.16 \\
\hline \multicolumn{5}{|l|}{ Treatment } \\
\hline IV (\%) & $6(20.1)$ & $4(66.7)$ & $2(8.7)$ & 0.001 \\
\hline SC $(\%)$ & $22(75.8)$ & $2(33.3)$ & $20(87)$ & $<0.0001$ \\
\hline $\mathrm{PO}(\%)$ & $1(3.4)$ & $0(0)$ & $1(4.3)$ & 0.6 \\
\hline \multicolumn{5}{|l|}{ Comorbidities } \\
\hline $\begin{array}{l}\text { Charlston, Mean (standard } \\
\text { deviation) }\end{array}$ & $2.72(+/-1.6)$ & $5.16(+/-1.8)$ & $2.08(+/-1.5)$ & $<0.0001$ \\
\hline Hypertension/HTA (\%) & $16(55)$ & $5(83.3)$ & $11(48)$ & 0.11 \\
\hline Dyslipidemia/DL (\%) & $12(41.3)$ & $4(66.7)$ & $8(34.8)$ & 0.15 \\
\hline Obesity (\%) & $10(34.5)$ & $1(16.7)$ & $9(39.1)$ & 0.30 \\
\hline $\begin{array}{l}\text { Chronic obstructive pulmonary } \\
\text { disease/COPD (\%) }\end{array}$ & $3(10.3)$ & $3(50)$ & $0(0)$ & $<0.0001$ \\
\hline Heart disease (\%) & $8(27.5)$ & $4(66.6)$ & $4(17.4)$ & 0.01 \\
\hline Chronic kidney disease/CKD (\%) & $7(24.1)$ & $4(66.6)$ & $3(13)$ & 0.006 \\
\hline Diabetes mellitus /DM (\%) & $7(24.1)$ & $3(50)$ & $4(17.4)$ & 0.001 \\
\hline Previous or current smokers (\%) & $9(31)$ & $3(50)$ & $6(26)$ & 0.26 \\
\hline
\end{tabular}

Conclusion: The rate of COVID19 hospitalization in our patients was comparable to the general population's (between $19-24 \%$ from 60 years plus) and the risk of in-patient death is also similar, around $24 \%{ }^{1}$. Our study suggests that neither their ID nor their treatment influences their risk of a worse outcome.

COPD, DM and previous heart disease were associated with worse outcome; however it seems that the main prognostic factor was the overall impact of comorbidities associated; as measured by the Charlston's index, being significantly higher in the patients with a fatal outcome.

A fatal outcome was more likely in IV biologics, however it could be explained by indication bias probably due to higher comorbidity and disability in these patients rather than an independent prognostic variable.

\section{REFERENCES:}

[1] Mesas AE et al. Predictors of in-hospital COVID-19 mortality: A comprehensive systematic review and meta-analysis exploring differences by age, sex and health conditions. PLoS One. 2020 Nov 3;15(11)

[2] Jovani, $V$ et al.Incidence of severe COVID-19 in a Spanish cohort of 1037 patients with rheumatic diseases treated with biologics and JAK-inhibitors. ARD 2020-218152.

Disclosure of Interests: None declared

DOI: 10.1136/annrheumdis-2021-eular.4000

\section{AB0707 RHEUMATOLOGY PATIENT CARE IN THE COVID-19 PANDEMIC: TELEMEDICINE, DELEGATION, PATIENT SATISFACTION AND VACCINATION BEHAVIOUR}

T. Thiele ${ }^{1}$, S. Beider ${ }^{1}$, H. Kühl ${ }^{1}$, G. Miehlke ${ }^{1}$, A. Cossmann ${ }^{1}$, A. Holz ${ }^{2}$, C. Happle ${ }^{3}$, K. Hoeper ${ }^{1}$, T. Witte ${ }^{1}$, A. Jabonka ${ }^{1}$, D. Ernst ${ }^{1} .{ }^{1}$ Medizinische Hochschule Hannover, Clinic for Rheumatology and Immunology, Hannover, Germany; ${ }^{2}$ Rheumatologische Facharztpraxis, Rheumatologie, Hildesheim, Germany; ${ }^{3}$ medizinische Hochschule Hannover, Clinic for Pediatric Pneumology, Allergology and Neonatology, Hannover, Germany

Background: Use of telemedicine in Germany has increased due to the COVID19 lockdown. Between March and May 2020, government restrictions led to cancellation of routine outpatient appointments to limit viral spread and optimize resources.

Objectives: This study assesses patient satisfaction of follow-up telemedicine appointments among patients known to be in disease remission, attending either secondary or tertiary care Rheumatology clinics. Appointments were conducted either by a rheumatologist or a qualified medical assistant for rheumatology (RFA). Additional data regarding perceived concerns aris ing from the COVID-19 pandemic as well as attitudes to vaccination were collected.

Methods: Methods: Patients not requiring adjustment of their DMARDs at the two previous attendances were considered stable. At cancellation of the planned attendance, patients were offered participation in the study and provided verbal informed consent. Participants were randomized to a telemedicine appointment by either a physician or RFA. Telemedicine appointments consisted of a standardized patient interview, including assessment of disease activity (modified CDAI score), attitudes to vaccination as well as current vaccine status and concerns about COVID-19. Following participation, all patients received a pseudonymized postal questionnaire to evaluate appointment satisfaction (FAPI-Score)

Results: In total $112 / 116$ (96\%) patients that were offered appointments, participated in the study (RA 50\%, axSpA 30\%, PsA 20\%). Of these $88 / 112$ (79\%) returned their postal questionnaires. Overall patient satisfaction was excellent (mean 4.3/5 modified FAPI score) and did not differ between care setting or clinical status of the interviewer. RFAs conducted $19 / 112(17 \%)$ of appointments, $6(32 \%)$ of which required additional physician intervention. Change of DMARDs occurred in 19/112 (17\%) appointments. Patients reporting a pain score $\geq 7$ (VAS 1-10) were most dissatisfied with the telemedicine appointment $(p=0.036)$. Concerns about COVID-19 correlated with disease activity: high disease activity $(p=0.031)$, presence of tender joints $(p=0.001)$, high pain levels $(p=0.009)$ correlated with concern of contracting COVID-19 or experiencing severe disease course. Only $38 \%$ of the patients had been vaccinated against pneumococci in the past 5 years and $54 \%$ had been vaccinated against influenza in 2019/2020

Conclusion: Telemedicine can contribute to patient care in stable patients. RFAs can also contribute to patient care especially for follow-up appointment when patients are in remission. Vaccination rates and motivation needs to be improved as influenza and pneumococcal vaccination is recommended to all patients with rheumatic diseases without contraindications.

Disclosure of Interests: None declared DOI: 10.1136/annrheumdis-2021-eular.4005 